\title{
A novel modification of Bardach's two-flap palatoplasty for the repair of a difficult cleft palate
}

\author{
Mohd Altaf Mir, Nishank Manohar, Debarati Chattopadhyay, Sameer S Mahakalkar \\ Department of Burns and Plastic Surgery, All India Institute of Medical Sciences, Rishikesh, India
}

\begin{abstract}
Bardach described a closure of the cleft utilizing the arch of the palate, which provides the length needed for closure and is most effective only in narrow clefts. Herein, we describe a case where we utilized Bardach's two-flap technique with a vital and easy modification, done to allow closure of a wide cleft palate and to prevent oronasal fistula formation at the junction of the hard and soft palate, which are otherwise difficult to manage with conventional flaps. The closed palate showed healthy healing, palatal lengthening, and no oronasal regurgitation. We advise using this modification to achieve the goals of palatal repair in difficult cases where tension-free closure would otherwise be achieved with more complex flap surgical techniques, such as free microvascular tissue transfer.
\end{abstract}

Keywords Cleft palate / Cleft lip / Cleft repair

\author{
Correspondence: Mohd Altaf Mir \\ Department of Burns and Plastic \\ Surgery, All India Institute of Medical \\ Sciences (AlIMS), Virbhadra Marg \\ Rishikesh Uttarakhand, Rishikesh \\ 249203, India \\ Tel: $+91-9897561144$ \\ Fax: +91-1353564869 \\ E-mail:draltafmir@gmail.com
}

Received: March 14, $2020 \bullet$ Revised: June 24, $2020 \bullet$ Accepted: June 27, 2020

pISSN: 2234-6163 • elSSN: 2234-6171 • https://doi.org/10.5999/aps.2020.00416• Arch Plast Surg 2021;48:75-79

\section{INTRODUCTION}

Cleft palate is among the most frequent congenital craniofacial anomalies worldwide. Numerous methods have been described for repairing defects in the palate. Most techniques include raising mucoperiosteal flaps and advancing them along the midline to close the defect. These include von Langenbeck's palatoplasty, the Veau-Wardill-Kilner technique, and Bardach's two-flap palatoplasty [1]. von Langenbeck's palatoplasty is the most commonly used technique worldwide and involves raising bipedicled mucoperiosteal flaps to cover the cleft. Although this procedure is simple, the speech outcomes are poor because of inadequate retroposition [1]. The Veau-Wardill-Kilner technique is a simple V-to-Y incision on the hard palate with closure, thus producing pushback in the palate. It produces excellent results in terms of speech outcomes because it achieves palatal lengthening, but it has the disadvantage of creating larger raw areas anteriorly [1]. Bardach described reconstruction of the cleft utilizing the arch of the palate, which provides the length needed for closure. This technique is essentially a modification of von Langenbeck's technique by extending the lateral alveolar relaxing incisions to the edge of the cleft. However, Bardach's technique is most effective only in narrow clefts [2]. Herein, we describe a case where we utilized Bardach's two-flap technique with a vital and easy modification, done to allow closure of a wide cleft palate.

\section{CASE}

A 7-year-old otherwise healthy female child presented to our outpatient office with a Veau II incomplete cleft in the soft palate extending to the hard palate (Figs. 1, 2A). After thorough preoperative investigations and valid informed consent, palatoplasty was performed. The cleft in the palate extended from the uvula posteriorly to the posterior hard palate with a total length of $3 \mathrm{~cm}$ antero-posteriorly. The width of the cleft at the junction 
of the hard and soft palate was $1.8 \mathrm{~cm}$. The maximum width of the cleft palate was $2.3 \mathrm{~cm}$ and it was $6 \mathrm{~mm}$ posterior to the junction of the hard and soft palate. The total palate length as measured from the central mid-alveolar ridge to the tip of the uvula was $5.5 \mathrm{~cm}$ (Fig. 1). In light of the technical difficulty in closure, the cleft was managed with our own modification of Bardach's technique described below.

The patient was prepared for palatoplasty under general anesthesia after obtaining consent from her father for general anesthesia, palatoplasty, and any modifications needed. Consent was also obtained from the patient's father for preoperative, intraoperative, and postoperative photography and videography and publication for educational purposes in any scientific journal.

After induction of general anesthesia, a Dingman self-retaining mouth gag was placed to allow good exposure of the entire palate, as shown in Fig. 1. The palate was infiltrated with a solution of adrenaline at a concentration of 1:200,000 for effective vasoconstriction and hydrodissection, and then markings were made for Furlow's double opposing smaller Z-plasty and Bardach's palatoplasty as depicted in Fig. 2A. The soft palate was then repaired using the modified Furlow's double opposing smaller Zplasty technique, which included relatively short limbs, as depicted in Fig. 2B, that preserved the vascularity of the smaller Zplasty flaps. Thereafter, incisions were made in the hard palate starting along the lateral alveolar margins and extending to the margins of the cleft bilaterally. Mucoperiosteal flaps based on the greater palatine vessels were raised as depicted in Fig. 2C.

\section{Fig. 1. Intraoperative photograph of Veau II cleft palate}

The cleft in the palate extended from the uvula posteriorly to the posterior hard palate, with a total length of $3 \mathrm{~cm}$ antero-posteriorly. The width of the cleft at the junction of the hard and soft palate was $1.8 \mathrm{~cm}$. The maximum width of the cleft palate was $2.3 \mathrm{~cm}$ and it was $6 \mathrm{~mm}$ posterior to the junction of the hard and soft palate. The total palate length as measured from the central mid-alveolar ridge to the tip of the uvula was $5.5 \mathrm{~cm}$.

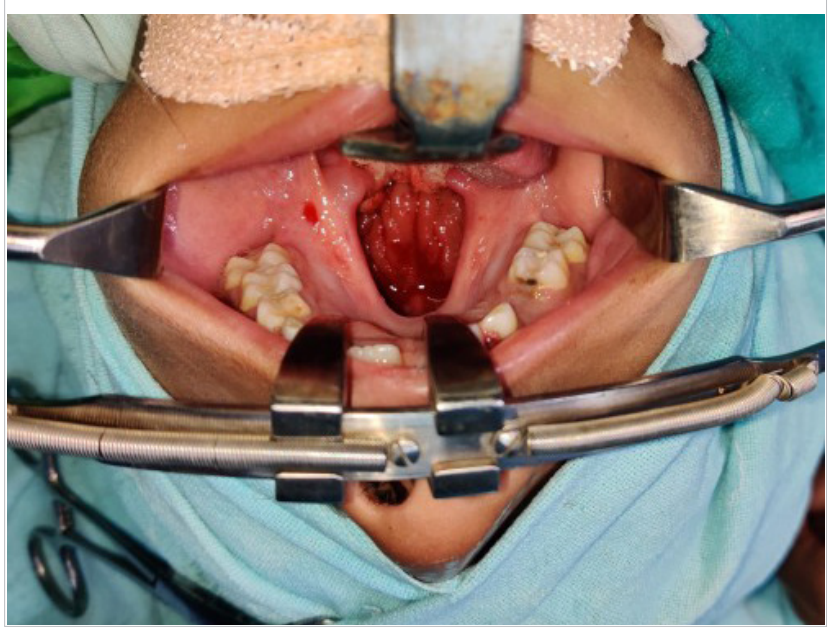

Since the cleft was wide initially, the vascular pedicles were skeletonized and the pterygoid hamulus was fractured to increase the mobility of the flaps. When the flaps were still under tension, bilateral greater palatine foraminotomy was also done. However, the flaps could still not be advanced medially for tension-free closure. We did not extend the lateral incisions beyond the maxillary tuberosity to avoid devascularization of the oral side smaller Z-plasty flaps. However, subperiosteal dissection was performed to achieve vascular pedicle skeletonization and fracture of the pterygoid hamulus. The two flaps were then transposed medially at right angles to cover the defect and sutured to each other in the midline transversely using Vicryl 4-0

\section{Fig. 2. Diagrammatic representation of Mir's two flap palatoplasty}

(A) Artistic depiction of Veau II cleft palate with marking of flaps. This figure depicts intraoperative flap markings of modified Furlow's double opposing Z-plasty with shorter limbs of $5 \mathrm{~mm}$ for soft palate reconstruction (flaps $C$ and $D$ on oral side), while flaps $A$ and $B$ are modifications of Bardach's two-flap palatoplasty for hard palate reconstruction. (B) Artistic depiction of modified Furlow's palatoplasty. This figure depicts raising of oral-side smaller Z-plasty flaps ( $C$ and $D$ ) and nasal-side opposing smaller Z-plasty flaps ( $E$ and $H$ with $5-\mathrm{mm}$ limbs. It also shows modifications of Bardach's two flaps $(A$ and $B)$ for hard palate reconstruction. (C) Artistic depiction of the raising of a modified version of Bardach's two flaps. This figure shows raised bilateral mucoperiosteal flaps ( $A$ and $B$ ) based on the greater palatine vessels for hard palatal reconstruction. (D) Artistic depiction of final closure of cleft palate. This figure depicts the completion of modified Furlow's palatoplasty ( $C$ and $D$ are oral-side Z-plasty flaps) and our modified Bardach's two-flap ( $A$ and $B$ ) transposition palatoplasty to overcome the difficulty of closure of wider clefts in the region of the hard palate. The areas marked 1 and 2 are the two small residual semilunar raw areas.
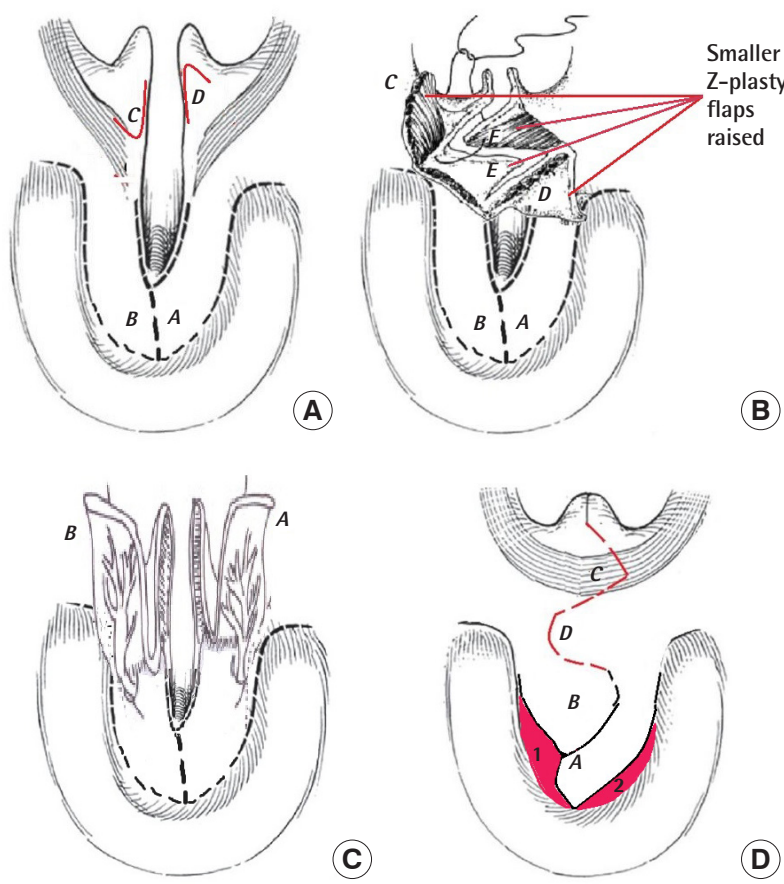

(D) 


\section{Fig. 3. Immediate postoperative photograph}

This shows the final inset of our modification of Bardach's palatoplasty flaps with a transverse stitch line.

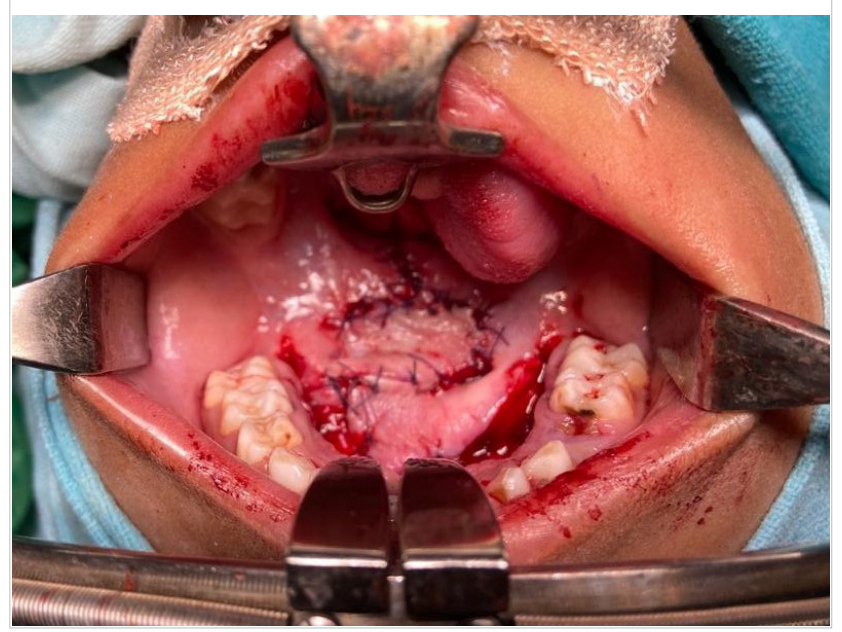

sutures. The resulting stitch line was then oriented transversely, as shown in Fig. 2D and Fig. 3. The anterior and lateral raw areas were then left to heal by secondary intention after ensuring hemostasis (Fig. 3).

The procedure described herein led to tension-free closure of the wide cleft in the palate and simultaneously produced a lengthening of the palate by $5 \mathrm{~mm}$. The patient's postoperative course was uneventful, and she was able to accept oral intake 6 hours after surgery. There was no incidence of bleeding, infection, and dehiscence or airway compromise. The two flaps healed adequately, with no evidence of any palatal fistula at 6 weeks. The postoperative anteroposterior curved length of the soft palate was $2.5 \mathrm{~cm}$, and that of the hard palate was $3.5 \mathrm{~cm}$. There was a net gain in length of $5 \mathrm{~mm}$ in the soft palate and in the palate as a whole (Fig. 4).

\section{DISCUSSION}

Cleft palate surgery has a long history, and it has evolved through modifications made to existing surgical procedures to tackle problems faced by surgeons. The challenge of palatoplasty is no longer just to achieve tension-free closure of the cleft and to prevent palatal fistula, but also to increase palatal length, to improve speech outcomes, and to have a minimal effect on maxillofacial growth [3].

The oldest technique that is still widely used for palatoplasty is von Langenbeck's technique, which involves raising two bipedicled mucoperiosteal flaps and medially advancing them to close incomplete clefts of the palate. Modifications to this technique include re-approximation of the levator veli palatini muscle and intravelar veloplasty to reconstruct the muscular sling and im-

\section{Fig. 4. Follow-up photograph at 6 weeks}

This photograph shows excellent healing of both Furlow's double opposing Z-plasty and our modification of Bardach's palatoplasty without any complications. The postoperative anteroposterior curved length of the soft palate was $2.5 \mathrm{~cm}$, and that of the hard palate was $3.5 \mathrm{~cm}$. There was net gain in length of $5 \mathrm{~mm}$ in the soft palate and in the palate as a whole.

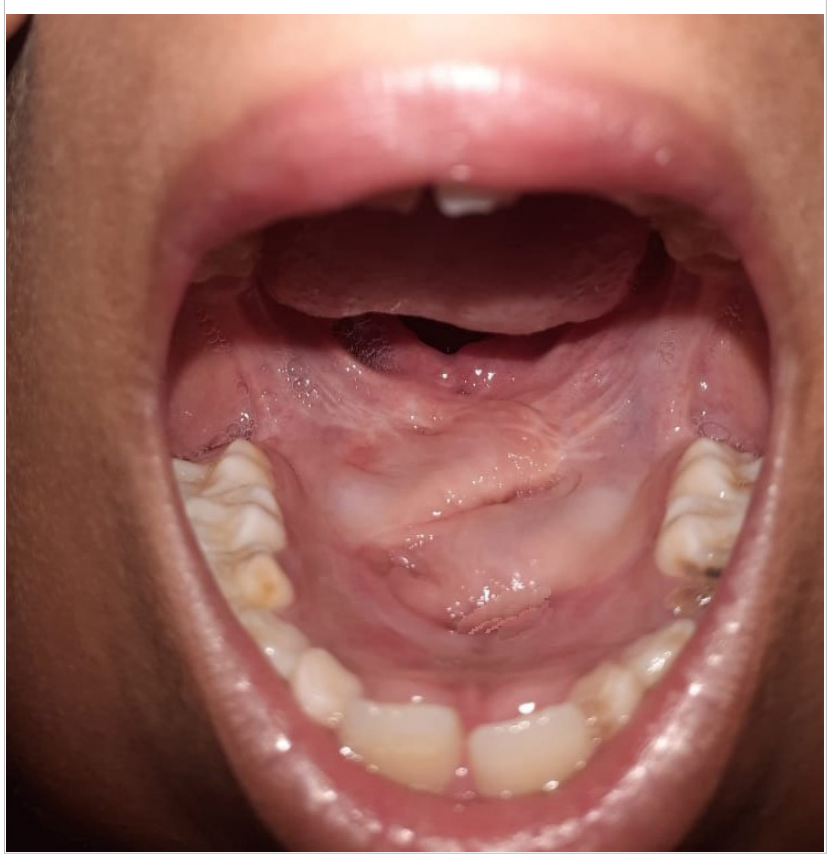

prove speech outcomes [4]. However, this procedure does not provide adequate palatal lengthening, and the V-Y pushback technique was developed as a modification of von Langenbeck's procedure to increase the anteroposterior length of the palate. This technique involves making a V-to-Y incision and closure on the hard palate. The pushback technique leads to improved long-term speech outcomes by lengthening the palate and repositioning the levator muscle in a more favorable position [5].

Bardach [2] first devised the two-flap palatoplasty in 1967. In this technique, mucoperiosteal flaps are released from the cleft margins to close relatively narrow clefts. The design of this flap depends entirely on the greater palatine neurovascular pedicle, and it has the advantage of greater versatility for cleft coverage.

In 1985, Furlow [6] introduced a novel method of palatal closure in patients with cleft palate using two opposing Z-plasties in the soft palate, which after transposition in the midline create a palatal muscle sling and also increase the length of the palate. The hard palate is closed without lateral relaxing incisions and the resulting scar in the hard palate is only in the midline. Further use of bilateral buccal mucosal flaps in conjunction with Furlow's double opposing Z-palatoplasty has also been described as a way to cover the denuded areas on the posterior hard palate [7]. 
Surgical repair of a wide cleft palate is a surgical challenge. Using the above-described techniques to close a wide cleft may place the palatal tissue under high tension, increasing the risk of postoperative oronasal fistula formation. Other ancillary procedures for tension-free closure in a wide cleft palate include the following manoeuvres: fracture of the hamulus, careful dissection into the space of Ernst, hard palate mucoperiosteal undermining, and stretching of the greater palatine neurovascular bundles [8].

Traditionally, the fixed position of the neurovascular bundles as they originate from their bony foramina has limited the scope of successful palatoplasty procedures. An option for managing the greater palatine structures is osteotomy of the greater palatine foramen, which was first described by Limberg as a way to free the neurovascular bundle, thereby increasing mobility of the palatal flaps and reducing the tension of closure. However, osteotomy is an invasive, trauma-inducing procedure and retrograde displacement achieved through osteotomy can be effective only if it is performed extensively; however, extensive osteotomy has unpredictable outcomes, and can be more harmful than beneficial [9].

Bilateral transposition flaps, as we have described for the repair of wide cleft palates in children, are a safe and easy procedure that can be applied in cases where traditional flaps and manoeuvres are unable to produce tension-free closure in combination with the modified Furlow's double opposing smaller Z-plasty technique, which includes relatively shorter limbs as performed by Yamaguchi et al. [10,11] between 2007 to 2014 and reported in 2016.

If performed alone it is safe to extend the incision beyond the maxillary tuberosity to free the neurovascular bundle, to fracture the hamulus, and to perform foraminotomy to increase the mobility of the palatal flaps and to reduce the tension of closure. However, when combined with Furlow's double opposing smaller Z-plasty, the incision should not be extended beyond the maxillary tuberosity to avoid the devascularization of the oral side of smaller Z-plasty flaps; instead, subperiosteal undermining is sufficient.

Nasal side closure is challenging, but can be achieved with vomerine or facial artery myomucosal flaps. In our case, vomerine flaps were used.

We achieved a significant net gain of $5 \mathrm{~mm}$ in the anteroposterior curved palatal length, which could be attributed to Furlow's smaller Z-plasty and the transverse orientation of our modified Bardach's flaps, avoiding anteroposterior scar orientation. However, limitations include dog ear deformities, challenging nasal side closure, and a short follow-up (in our case). Further welldesigned studies with large samples are needed to augment the evidence. We are in the process of submitting a protocol for a well-designed randomized controlled non-inferiority trial to the institutional review board to prove the efficacy of this technique.

We advise our modification to achieve the goals of palatal repair in difficult cases of Veau II incomplete cleft where tensionfree closure would otherwise be achieved with more complex flap surgical procedures, such as free microvascular tissue transfer. However, further studies are needed to augment the evidence.

\section{NOTES}

\section{Conflict of interest}

No potential conflict of interest relevant to this article was reported.

\section{Ethical approval}

The study was performed in accordance with the principles of the Declaration of Helsinki. Written informed consent was obtained.

\section{Patient consent}

The patient's parent provided written informed consent for the publication and the use of her images.

\section{Author contribution}

Conceptualization: MA Mir. Data curation: MA Mir. Formal analysis: MA Mir. Methodology: MA Mir. Project administration: MA Mir. Visualization: MA Mir. Writing - original draft: N Manohar, SS Mahakalkar. Writing - review \& editing: MA Mir, D Chattopadhyay.

\section{ORCID}

Mohd Altaf Mir https://orcid.org/0000-0001-8833-4125

Nishank Manohar https://orcid.org/0000-0001-9600-7781

Debarati Chattopadhyay

https://orcid.org/0000-0002-0167-7561

Sameer S Mahakalkar https://orcid.org/0000-0001-7131-9009

\section{REFERENCES}

1. Thomas C. Repair of cleft palate: evolution and current trends. J Cleft Lip Palate Craniofac Anomal 2015;2:6-10.

2. Bardach J. Two-flap palatoplasty: Bardach's technique. Oper Tech Plast Reconstr Surg 1995;2:211-4.

3. Leow AM, Lo LJ. Palatoplasty: evolution and controversies. Chang Gung Med J 2008;31:335-45.

4. Trier WC, Dreyer TM. Primary von Langenbeck palatoplas- 
ty with levator reconstruction: rationale and technique. Cleft Palate J 1984;21:254-62.

5. Paniagua LM, Collares MV, Costa SS. Comparative study of three techniques of palatoplasty in patients with cleft of lip and palate via instrumental and auditory-perceptive evaluations. Int Arch Otorhinolaryngol 2010;14:18-31.

6. Furlow LT Jr. Cleft palate repair by double opposing Z-plasty. Plast Reconstr Surg 1986;78:724-38.

7. Mann RJ, Fisher DM. Bilateral buccal flaps with double opposing Z-plasty for wider palatal clefts. Plast Reconstr Surg 1997;100:1139-45.

8. LaRossa D, Jackson OH, Kirschner RE, et al. The Children's Hospital of Philadelphia modification of the Furlow double- opposing Z-palatoplasty: long-term speech and growth results. Clin Plast Surg 2004;31:243-9.

9. Aboul-Wafa AM. Islandized mucoperiosteal flaps: a versatile technique for closure of a wide palatal cleft. Can J Plast Surg 2012;20:173-7.

10. Yamaguchi $\mathrm{K}$, Lonic D, Lee CH, et al. Modified Furlow palatoplasty using small double-opposing Z-plasty: surgical technique and outcome. Plast Reconstr Surg 2016;137: 1825-31.

11. Yamaguchi K, Lonic D, Lo LJ. Modified Furlow palatoplasty using small double-opposing Z-plasty for patients with cleft lip and/or palate. Plast Reconstr Surg Glob Open 2016;4 (9S): 16 . 